\title{
TRITERPENE GLYCOSIDES OF LEGUMINOSAE
}

I. Chemical Characteristics Of Phaseoloside $\mathrm{E}$

V. Ya. Chirva, L. G. Kretsu, and P. K. Kintya

Khimiya Prirodnykh Soedinenii, Vol. 6, No. 3, pp. 377-378, 1970

UDC $547.913-547.917$

Information on the saponins of the bean is fragmentary. Japanese workers have isolated from Phaseolus radiatus var. aureus a crystalline saponin containing as the aglycone soyasapogenol $\mathrm{C}$ and, in the carbohydrate moiety, glucuronic acid, glucose, arabinose, and rhamnose.

In view of this, the most widespread species Phaseolus vulgaris L. (kidney bean) has attracted attention. A methanolic extract of the beans gave a positive reaction for triterpene glycosides. Sucrose was found among the inert compounds. On standing in the cold, the extract deposited a substance which, after two recrystallizations from ethanol was identical in melting point, specific rotation, and IR spectrum with $\beta$-sitosterol [2].

The glycoside fraction was partially purified from free sugars by precipitating the total saponins with acetone and subsequent butanol extraction of the precipitate in aqueous solution. Five triterpene glycosides were found in the organic extracts by chromatography in a thin layer of silica gel in butan-1-ol-ethanol-25\% ammonia (7:2:5 and $9: 2: 5)$, butan-1-ol-ethanol-water $(9: 2: 5)$, butan-1-ol-acetic acid-water $(4: 1: 5)$, and chloroform-methanolwater (55:35:10) systems, and we have named them, in order of increasing polarity, "phaseolosides" A, B, C, D, and $\mathrm{E}$.

By partition chromatography on silica gel in a chloroform-methanol-water (55:35:10) system, from the combined saponins we have obtained in the individual state phaseoloside $\mathrm{E}$ with $\mathrm{mp} 130^{\circ} \mathrm{C} ;[\alpha]_{\mathrm{D}}^{23}+54^{\circ}(\mathrm{c} 1.3, \mathrm{MeOH})$. The aglycone of this glycoside was identical in melting point, specific rotation, and chromatographic mobility with soyasapogenol $\mathrm{C}$. In an acid hydrolysate of the compound we found glucuronic acid, galactose, glucose, arabinose, and rhamnose. A sample of soyasapogenol $\mathrm{C}$ was kindly given to us by N. Toya and $\mathrm{S}$. Iseda (Japan).

\section{R E F ER ENCES}

1. N. Toya and S. Iseda, Nippon Nogei Kagaku Kaishi, 38, 273, 1964; C. A. 62, 16359, 1965.

2. W. Karrer, Konstitution und Vorkommen der organische Pflanzenstoffe, Basel, 855, 1958.

18 February 1970

Institute of Chemistry, AS Moldavian SSR 